\title{
ANALYSIS AND ASSESSMENT OF THE SECURITY METHOD AGAINST INCIDENTAL CONTAMINATION IN THE COLLECTIVE WATER SUPPLY SYSTEM
}

\section{ANALIZA I OCENA ZABEZPIECZENIA SYSTEMÓW ZBIOROWEGO ZAOPATRZENIA W WODE PRZED INCYDENTALNYM SKAŻENIEM}

\author{
Dawid Szpak, Barbara Tchórzewska - Cieślak \\ Politechnika Rzeszowska \\ e-mail: dsz@prz.edu.pl, cbarbara@prz.edu.pl
}

\begin{abstract}
The paper presents the main types of surface water incidental contaminations and the security method against incidental contamination in water sources. Analysis and assessment the collective water supply system (CWSS) protection against incidental contamination was conducted. Failure Mode and Effects Analysis (FMEA) was used. The FMEA method allow to use the product or process analysis, identification of weak points, and implementation the corrections and new solutions for eliminating the source of undesirable events. The developed methodology was shown in application case. It was found that the risk of water contamination in water-pipe network of the analyzed CWSS caused by water source incidental contamination is at controlled level.
\end{abstract}

Keywords: collective water supply system, incidental contamination, FMEA

Streszczenie: W pracy przedstawiono rodzaje incydentalnych skażeń źródet wody powierzchniowej oraz sposoby zabezpieczeń przed incydentalnym skażeniem. Przeprowadzono analizę $i$ ocene zabezpieczenia systemów zbiorowego zaopatrzenia $w$ wode (SZZW) przed incydentalnym skażeniem. Wykorzystano metodę analizy przyczyn $i$ uszkodzeń FMEA (ang. Failure Mode and Effect Analysis). Metoda FMEA pozwala na poddanie wyrobu lub procesu analizie, określenie słabych punktów, a następnie na wprowadzenie poprawek i nowych rozwiązań eliminujących źródła zdarzeń niepożądanych. Opracowana metodyka została przedstawiona na przykładzie aplikacyjnym. Stwierdzono, że ryzyko skażenia wody w sieci wodociagowej analizowanego SZZW spowodowane incydentalnym skażeniem źródła wody jest na poziomie kontrolowanym.

Stowa kluczowe: system zbiorowego zaopatrzenia $w$ wode, skażenie incydentalne, FMEA 
Analysis and assessment of the security method against incidental contamination... Analiza i ocena zabezpieczenia systemów zbiorowego zaopatrzenia w wodę...

\section{Wstęp}

Podstawowym celem przedsiębiorstw wodociągowych jest dostarczenie do konsumentów wody $\mathrm{w}$ odpowiedniej jakości, ilości oraz pod odpowiednim ciśnieniem [16]. Rezolucja Zgromadzenia Ogólnego ONZ nr 64/292 z dnia 28 czerwca 2010 roku stwierdza, że ,prawo do bezpiecznej i czystej wody pitnej i urządzeń sanitarnych jest prawem człowieka niezbędnym do pełnego cieszenia się życiem i korzystania ze wszystkich praw człowieka" [5]. W związku z tym systemy zbiorowego zaopatrzenia w wodę (SZZW) obsługujące duże aglomeracje miejskie charakteryzuje się pracą ciągłą o wysokim reżimie niezawodności i bezpieczeństwa $[14,18]$.

Większość dużych polskich miast pobiera wodę ze źródeł powierzchniowych, które są bardziej zanieczyszczone niż wody podziemne, natomiast w warunkach polskich dają możliwość osiągnięcia znacznie większych wydajności. Stan jakościowy wód powierzchniowych w Polsce jest określany za pomocą wskaźników fizycznych, chemicznych oraz biologicznych. Rozporządzenie [12] ustala trzy kategorie jakości wody:

- kategoria A1 - woda wymagająca prostego uzdatniania fizycznego, w szczególności filtracji oraz dezynfekcji,

- kategoria A2 - woda wymagająca typowego uzdatniania fizycznego i chemicznego, w szczególności utleniania wstępnego, koagulacji, flokulacji, dekantacji, filtracji, dezynfekcji (chlorowania końcowego),

- kategoria A3 - woda wymagająca wysokosprawnego uzdatniania fizycznego i chemicznego, w szczególności utleniania, koagulacji, flokulacji, dekantacji, filtracji, adsorpcji na węglu aktywnym, dezynfekcji (ozonowania, chlorowania końcowego).

Intensywny rozwój nowoczesnych technologii uzdatniania wody, a także szerokie korzystanie z funduszy Unii Europejskiej przyczyniło się w znacznym stopniu do poprawy jakości wody dostarczanej do konsumentów w ostatnich latach. Szczególnie duże ośrodki miejskie, dzięki wdrożeniu do zarządzania SZZW nowoczesnych technologii informacyjnych, posiadają szczelny system zabezpieczeń przed negatywnymi skutkami potencjalnych zdarzeń niepożądanych [17].

Głównym celem pracy jest przedstawienie metody analizy i oceny zabezpieczenia SZZW przed incydentalnym skażeniem oraz wskazanie optymalnych rozwiązań zabezpieczających mieszkańców przed spożyciem skażonej wody.

\section{Incydentalne skażenia źródel wody}

Zdarzenie incydentalne jest to zdarzenie, którego zajście stanowi poważne zagrożenie dla życia i zdrowia odbiorców wody, powodujące znaczne szkody dla przedsiębiorstwa wodociągowego i którego wystąpienie dla zarządzającego SZZW jest trudne do przewidzenia [8, 15]. Zgodnie z Rozporządzeniem [13] woda jest bezpieczna wtedy, gdy jest wolna od mikroorganizmów chorobotwórczych i pasożytów w liczbie stanowiącej potencjalne zagrożenie dla zdrowia ludzkiego, substancji chemicznych $w$ ilościach zagrażających zdrowiu oraz nie ma 
agresywnych właściwości korozyjnych i spełnia podstawowe wymagania mikrobiologiczne i fizykochemiczne podane w załącznikach do Rozporządzenia [13]. Skażenie wody w sieci wodociągowej może być wynikiem skażenia wody w źródle, nieefektywnego systemu uzdatniania wody, skażenia wody znajdującej się w podsystemie dystrybucji wody lub wtórnego skażenia wody [16]. W niniejszej pracy analizie poddano wyłącznie zdarzenia niepożądane mogące skutkować skażeniem wody w źródle. Zagrożenie dla konsumentów stanowią zanieczyszczenia, których usunięcie wymaga korekt w konwencjonalnym uzdatnianiu wody, zanieczyszczenia które mogą być usunięte po uruchomieniu alternatywnej technologii uzdatniania oraz zanieczyszczenia których proces uzdatniania nie jest w stanie usunąć [7]. Każda zmiana w procesie uzdatniania wymaga akceptacji inspektora sanitarnego [13] i niesie za sobą ryzyko niespełnienia wymagań stawianych wodzie przeznaczonej do spożycia. Przykładowo zwiększenie dawki chloru zwiększa prawdopodobieństwo powstawania trihalometanów (THM-ów) w sieci wodociągowej.

Do głównych przyczyn incydentalnych skażeń źródeł wody zalicza się [7, 15]:

- zdarzenia o znamionach poważnej awarii oraz poważne awarie, których rejestr prowadzi Główny Inspektorat Ochrony Środowiska, np. zanieczyszczenie rzeki substancjami ropopochodnymi spowodowane katastrofą w ruchu lądowym,

- niekontrolowany wyciek nieoczyszczonych ścieków sanitarnych z oczyszczalni ścieków,

- celowe działanie osób trzecich: działania wojenne, atak terrorystyczny lub cyberterrorystyczny, atak psychopaty lub akt wandalizmu,

- intensywne opady deszczu w górze rzeki, powódź,

- suszę.

Szczególnie niebezpieczne dla zdrowia i życia konsumentów są [2, 9]:

- wirusy występujące w wodzie, tj.: Polio 1,2, Coxsackie A, Coxsackie B, ECHO, Adenovirus, Hepatitis A,E, Rotavirus, Norwalk,

- bakterie chorobotwórcze występujące w wodzie, tj. Salmonella typhi, S. paratyphi A, B, C, Shigella sonnei, S. Feri, S. Dyteria, Escherichia coli, Francisella tularensis, Vibrio cholerae, Mycobacterium tuberculosis, Leptospira biflexa, Bacillus cereus, Clostridium perfringens, C. tetani, Yersinia enterocolitica, Y. pseudotuberculosis, Legionella sp.,

- antybiotyki oraz leki nieoznaczane w wodzie przeznaczanej do spożycia, stanowiące zagrożenie dla zdrowia konsumentów.

W związku z możliwością skażenia wody powierzchniowej ww. patogenami lub substancjami chemicznymi, niezbędne wydaje się opracowanie metodyki pozwalającej na ocenę zabezpieczenia SZZW przed incydentalnymi skażeniami. Skutki spożycia skażonej wody mogą być bardzo różne, od niegroźnych zatruć pokarmowych, poprzez dur brzuszny, zapalenie opon mózgowych, w skrajnych przypadkach śmierć. 
Analysis and assessment of the security method against incidental contamination... Analiza i ocena zabezpieczenia systemów zbiorowego zaopatrzenia w wodę...

Spożycie skażonej chemicznie wody najczęściej skutkuje wystąpieniem chorób wodopochodnych dopiero po wielu latach i nie dotyczy wszystkich konsumentów wody [4].

W praktyce wodociągowej wielokrotnie zdarzały się sytuacje, że konwencjonalne metody uzdatniania nie były w stanie usunąć skażenia lub skażenie nie zostało wykryte przez nieszczelny system monitoringu, co skutkowało poważnymi zatruciami konsumentów wody a nawet zejściami śmiertelnymi [8].

Incydentalne skażenie wody w SZZW może zostać wykryte przez [1, 20]:

- system wczesnego ostrzegania - informacja o jakości wody dostarczana jest $\mathrm{z}$ wyprzedzeniem na podstawie analizy jakości wody wykonywanej przez stację osłonowo - ostrzegawczą lub biomonitoring zlokalizowane w górze rzeki, co daje możliwość właściwej reakcji na rozwój sytuacji kryzysowej,

- system opóźnionego ostrzegania - analiza jakości wody wykonywana na ujęciu lub na SUW, konieczność zamknięcia SUW oraz dostawy wody do miasta z innych źródeł,

- system późnego ostrzegania - analiza jakości wody pobranej w podsystemie dystrybucji wody wykonywana przez przedsiębiorstwo wodociągowe oraz odpowiedni Państwowy Inspektorat Sanitarny zgodnie z [13]. Informacja o potencjalnym skażeniu przekazywana jest konsumentom za pomocą środków masowego przekazu.

W przypadku wykrycia skażenia, operator, jeżeli ma taką możliwość, powinien podjąć działania ograniczające negatywne skutki skażenia $[1,15,20]$ :

- intensyfikacja konwencjonalnego procesu uzdatniania wody,

- uruchomienie alternatywnej technologii uzdatniania,

- wykorzystanie wody zgromadzonej w zbiorniku wody surowej oraz zbiornikach sieciowych,

- uruchomienie alternatywnych źródeł wody,

- dostawa wody butelkowanej lub z beczkowozów.

\section{Analiza i ocena bezpieczeństwa SZZW z wykorzystaniem metody FMEA}

Metoda analizy przyczyn i uszkodzeń FMEA (ang. Failure Mode and Effect Analysis) pozwala na poddanie wyrobu lub procesu analizie, określenie słabych punktów, a następnie na wprowadzenie poprawek i nowych rozwiązań eliminujących źródła zdarzeń niepożądanych. W pracy przeprowadzono analizę FMEA procesu polegającego na zabezpieczeniu SZZW przed skutkami incydentalnego skażenia źródła wody. Metoda FMEA pozwala na wskazanie czynników, które mogą utrudniać lub uniemożliwiać spełnienie wymagań stawianych wodzie przeznaczonej do spożycia, a także może stanowić podstawę do wprowadzenia modernizacji zmniejszających ryzyko skażenia wody $[3,6]$. 
Ocenę ryzyka przeprowadza się na podstawie liczby priorytetowej ryzyka RPN (ang. Risk Priority Number) [11, 19]:

$$
\mathrm{RPN}=\mathrm{S} \cdot \mathrm{O} \cdot \mathrm{D}
$$

$\mathrm{S}$ (ang. Severity) - waga punktowa związana ze znaczeniem zdarzenia niepożądanego,

O (ang. Occurence) - waga punktowa związana z częstotliwością występowania zdarzenia niepożądanego,

D (ang. Detection) - waga punktowa związana z możliwością wykrycia zdarzenia niepożądanego.

W tabelach 1, 2 oraz 3 przedstawiono propozycję wag punktowych dla parametrów $\mathrm{S}, \mathrm{O}$ oraz D. Poszczególne parametry opisuje się liczbą całkowitą z przedziału od 1 do 10 , którą przyjmuje się na podstawie wiedzy ekspertów oraz doświadczenia eksploatatorów SZZW. Wynikiem analizy jest wartość RPN, przyjmująca wartości z przedziału od 1 do 1000 . Im wartość RPN jest większa, tym ryzyko skażenia wody w sieci wodociągowej spowodowane incydentalnym skażeniem wody w źródle jest większe.

Tabela 1. Kryteria $i$ wagi punktowe dla parametru $S[3,6]$

\begin{tabular}{|c|c|l|}
\hline $\mathrm{S}$ & $\begin{array}{c}\text { Znaczenie } \\
\text { zdarzeń } \\
\text { niepożądanych }\end{array}$ & \multicolumn{1}{|c|}{ FMEA procesu } \\
\hline 1 & bardzo małe & $\begin{array}{l}\text { nieznaczne pogorszenie parametrów organoleptycznych } \\
\text { wody niestanowiące zagrożenia dla procesu uzdatniania, } \\
\text { brak zagrożenia zdrowotnego dla konsumentów }\end{array}$ \\
\hline $2-3$ & małe & $\begin{array}{l}\text { znaczne pogorszenie parametrów organoleptycznych } \\
\text { wody wymagające intensyfikacji procesu zdatniania, } \\
\text { uciążliwość dla stacji uzdatniania wody (SUW), } \\
\text { konieczność zwiększenia dawki koagulanta, brak } \\
\text { zagrożenia zdrowotnego dla konsumentów }\end{array}$ \\
\hline $4-6$ & przeciętne & $\begin{array}{l}\text { incydentalne pogorszenie parametrów fizykochemicz- } \\
\text { nych, na które proces uzdatniania nie jest przygotowany, } \\
\text { zagrożenie zdrowotne dla konsumentów }\end{array}$ \\
\hline $7-8$ & duże & $\begin{array}{l}\text { incydentalne pogorszenie parametrów fizykochemicznych } \\
\text { lub bakteriologicznych, występowanie mikroorganizmów } \\
\text { chorobotwórczych, brak możliwości uzdatnienia wody } \\
\text { przez konwencjonalne metody uzdatniania, zagrożenie } \\
\text { zdrowotne dla konsumentów } \\
\text { rozległe skażenie bakteriologiczne wody, występowanie } \\
\text { mikroorganizmów chorobotwórczych, przekroczenie } \\
\text { parametrów fizykochemicznych, występowanie substancji } \\
\text { toksycznych, brak możliwości uzdatnienia wody przez } \\
\text { konwencjonalne metody uzdatniania, zagrożenie dla } \\
\text { zdrowia i życia konsumentów wody }\end{array}$ \\
\hline
\end{tabular}


Analysis and assessment of the security method against incidental contamination... Analiza i ocena zabezpieczenia systemów zbiorowego zaopatrzenia w wodę...

Tabela 2. Kryteria $i$ wagi punktowe dla parametru $O[3,6]$

\begin{tabular}{|c|c|c|c|}
\hline $\mathrm{O}$ & $\begin{array}{c}\text { Występowanie } \\
\text { zdarzeń } \\
\text { niepożądanych }\end{array}$ & FMEA procesu & $\begin{array}{c}\text { Częstotliwość } \\
\text { występowania } \\
{[1 / \mathrm{h}]}\end{array}$ \\
\hline 1 & nieprawdopodobne & $\begin{array}{c}\text { Skażenie jest bardzo mało } \\
\text { prawdopodobne }\end{array}$ & $<1 / 1000000$ \\
\hline 2 & bardzo rzadko & $\begin{array}{c}\text { Skażenie występuje bardzo } \\
\text { rzadko }\end{array}$ & 1 na 20000 \\
\hline 3 & rzadko & Skażenie występuje rzadko & 1 na 4000 \\
\hline $4-6$ & przeciętnie & $\begin{array}{c}\text { Skażenie występuje } \\
\text { umiarkowanie często }\end{array}$ & $\begin{array}{c}1 \text { na } 4000 \\
1 \text { na } 80\end{array}$ \\
\hline $7-8$ & często & Skażenie występuje często & $\begin{array}{c}1 \text { na } 40 \\
1 \text { na } 20\end{array}$ \\
\hline $9-10$ & bardzo często & $\begin{array}{c}\text { Skażenia praktycznie nie da } \\
\text { się uniknąć }\end{array}$ & $\begin{array}{c}1 \text { na } 8 \\
1 \text { na } 2\end{array}$ \\
\hline
\end{tabular}

Tabela 3. Kryteria $i$ wagi punktowe dla parametru $D[3,6]$

\begin{tabular}{|c|c|l|}
\hline D & $\begin{array}{c}\text { Wykrywalność } \\
\text { zdarzeń } \\
\text { niepożądanych }\end{array}$ & \multicolumn{1}{|c|}{ FMEA procesu } \\
\hline $1-2$ & bardzo wysoka & $\begin{array}{l}\text { Srodki weryfikacji prawie na pewno wykryją } \\
\text { potencjalne skażenie. Kompleksowy system } \\
\text { zabezpieczenia mieszkańców przed spożyciem } \\
\text { skażonej wody składający się z układu wczesnego, } \\
\text { opóźnionego oraz późnego ostrzegania. Możliwość } \\
\text { wykorzystania alternatywnej technologii uzdatnia- } \\
\text { nia, dostawy wody do miasta z alternatywnych } \\
\text { źródeł lub wykorzystania wody zgromadzonej } \\
\text { wzbiorniku wody surowej lub zbiornikach sieciowych }\end{array}$ \\
\hline $3-4$ & wysoka & $\begin{array}{l}\text { Srodki weryfikacji mają duże szanse wykrycia } \\
\text { potencjalnego skażenia. Układu wczesnego, } \\
\text { opóźnionego oraz późnego ostrzegania. Mała } \\
\text { dywersifikacja dostaw wody. }\end{array}$ \\
\hline $5-6$ & przeciętna & $\begin{array}{l}\text { Potencjalne skażenie może zostać wykryte przez } \\
\text { środki weryfikacji. System opóźnionego i późnego } \\
\text { ostrzegania. Brak stacji osłonowo - ostrzegawczej. }\end{array}$ \\
\hline $7-8$ & niska & $\begin{array}{l}\text { Wykrycie potencjalnej awarii przez środki } \\
\text { weryfikacji jest mało prawdopodobne. System } \\
\text { opóźnionego lub późnego ostrzegania. }\end{array}$ \\
\hline $9-10$ & bardzo niska & $\begin{array}{l}\text { Praktycznie brak szans na wykrycie potencjalnego } \\
\text { skażenia. Brak systemu ostrzegania i reagowania } \\
\text { w sytuacjach kryzysowych oraz możliwości } \\
\text { przeciwdziałania ich negatywnym skutkom. }\end{array}$ \\
\hline
\end{tabular}


Ocena ryzyka polega na porównaniu otrzymanej wartości z przyjętą skalą ryzyka [11]:

- ryzyko tolerowane $\left(\mathrm{r}_{\mathrm{T}}\right)-\mathrm{RPN} \leq 40$,

- ryzyko kontrolowane $\left(\mathrm{r}_{\mathrm{K}}\right)-40<\mathrm{RPN} \leq 100$,

- ryzyko nieakceptowane $\left(\mathrm{r}_{\mathrm{N}}\right)-\mathrm{RPN}>100$.

\section{Przykład aplikacyjny}

Na rysunku 1 przedstawiono sposób zabezpieczenia SZZW miasta powiatowego południowo - wschodniej Polski przed incydentalnym skażeniem. Miasto korzysta Z ujęcia brzegowo - przewodowego o wydajności około $17000 \mathrm{~m}^{3} / \mathrm{d}$, SZZW zaopatruje w wodę około 35000 mieszkańców. Inne możliwe rozwiązania zostały szczegółowo przedstawione $\mathrm{w}[1,20]$.

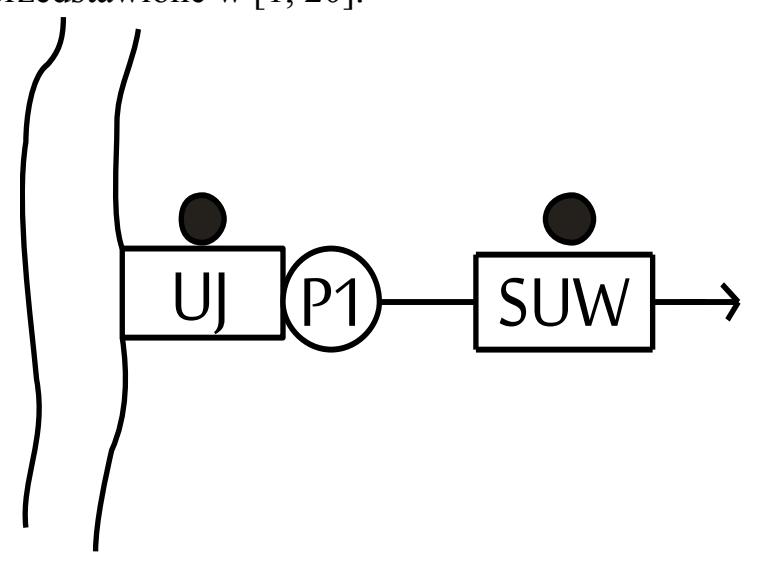

Rys. 1 Sposób zabezpieczenia SZZW przed incydentalnym skażeniem [20]

Oznaczenia na rysunku:

UJ - ujęcie wody,

P1 - pompownia pierwszego stopnia,

SUW - stacja uzdatniania wody,

- $\quad-$ miejsce poboru próbek.

Pobór prób wody odbywa się na ujęciu lub na stacji uzdatniania wody (SUW) kilkukrotnie w ciągu doby. Na podstawie uzyskanych wyników analiz jakości wody operator podejmuje stosowne decyzje eksploatacyjne. Ze względu na odstęp czasowy pomiędzy poszczególnymi pomiarami, istnieje ryzyko przepływu wody o nieodpowiedniej jakości do podsystemu dystrybucji wody. Ponadto w sieci wodociągowej prowadzony jest kontrolny oraz przeglądowy monitoring jakości wody zgodnie z [13].

$\mathrm{Na}$ podstawie powyższych informacji przyjęto odpowiednie wartości parametrów $\mathrm{S}$, $\mathrm{O}$ oraz D i wyznaczono RPN, co przedstawiono w tabeli 1. Przeanalizowano kilka potencjalnych zdarzeń niepożądanych związanych z nagłym pogorszeniem jakości wody w źródle mogących skutkować skażeniem wody w sieci wodociągowej. Praktyczne wskazówki postępowania w sytuacjach kryzysowych związanych z zaopatrzeniem $\mathrm{w}$ wodę zostały przedstawione $\mathrm{w}$ pracy [10]. Skutki potencjalnej sytuacji kryzysowej zmniejsza rozcieńczenie skażonej wody, wodą znajdującą się w sieci oraz zbiornikach wodociągowych [20]. 
Analysis and assessment of the security method against incidental contamination... Analiza i ocena zabezpieczenia systemów zbiorowego zaopatrzenia w wodę...

Tabela 4. FMEA procesu [3]

\begin{tabular}{|c|c|c|c|c|c|c|c|c|}
\hline 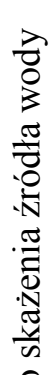 & 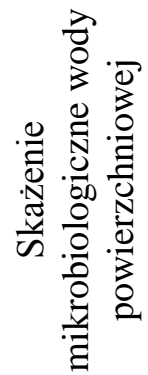 & 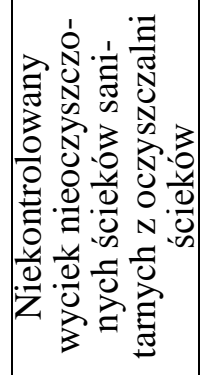 & 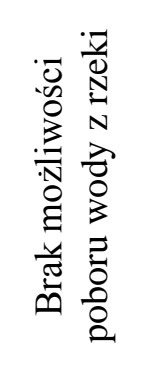 & $a$ & $N$ & $n$ & 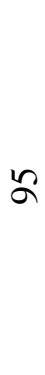 & 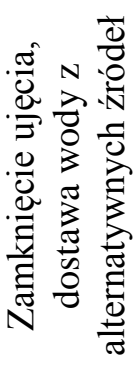 \\
\hline 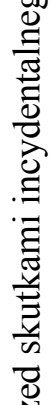 & 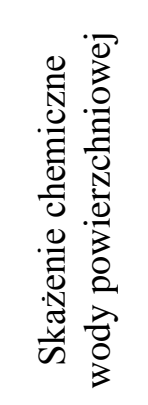 & 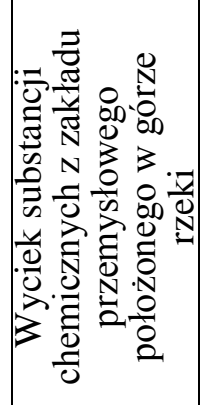 & 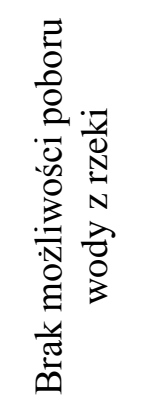 & $\infty$ & $N$ & $n$ & $\infty$ & 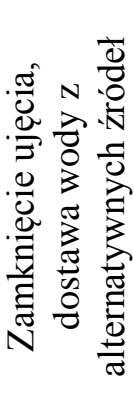 \\
\hline 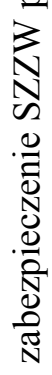 & 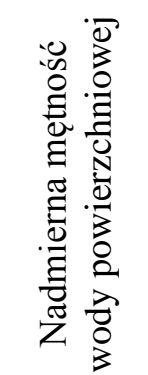 & 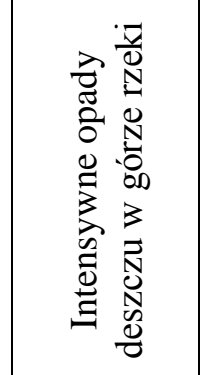 & 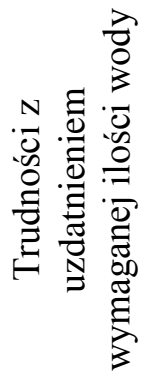 & $m$ & in & $n$ & $\stackrel{2}{2}$ & 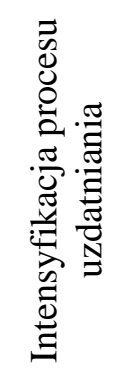 \\
\hline 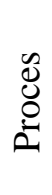 & 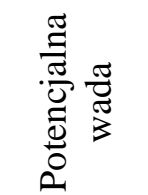 & 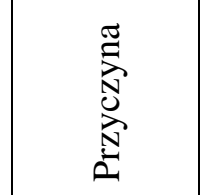 & 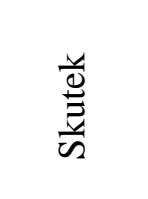 & $\sim$ & 0 & D & $\bar{\alpha}$ & 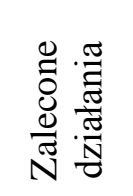 \\
\hline
\end{tabular}

Na podstawie przeprowadzonej analizy stwierdza się, że ryzyko skażenia wody w sieci wodociągowej spowodowane incydentalnym skażeniem źródła wody jest na poziomie kontrolowanym. Przedsiębiorstwo wodociągowe powinno rozważyć rozbudowę istniejącego systemu zabezpieczeń i obniżenie ryzyka do poziomu tolerowanego, o ile jest to ekonomicznie i technicznie uzasadnione. Największe zagrożenie dla bezpieczeństwa konsumentów wody stanowią zdarzenia związane $\mathrm{z}$ biologicznym skażeniem źródła wody. 


\section{Podsumowanie}

Metoda FMEA pozwala na określenie słabych punktów procesu polegającego na zabezpieczeniu SZZW przed skutkami incydentalnego skażenia źródła wody oraz wyznaczenie ryzyka wystapienia zdarzenia niepożądanego. Ocenę zabezpieczenia SZZW przed incydentalnym skażeniem przeprowadzono na podstawie liczby priorytetowej ryzyka RPN. Ponieważ całkowite wyeliminowanie powstawania zdarzeń niepożądanych jest niemożliwe, przedsiębiorstwo wodociągowe powinno podjąć działania mające na celu obniżenie ryzyka do poziomu tolerowanego.

Należy rozważyć rozbudowę analizowanego systemu zabezpieczeń mieszkańców o stację osłonowo - ostrzegawczą zlokalizowaną w górze rzeki. Wykorzystanie stacji osłonowo - ostrzegawczej pozwala na wczesne wykrycie wody o nieodpowiedniej jakości oraz pozwala operatorom na podejmowanie racjonalnych decyzji we wczesnym etapie rozwoju sytuacji kryzysowej. Szczególnie korzystnym rozwiązaniem jest współpraca stacji osłonowo ostrzegawczej ze zbiornikiem wody surowej lub zbiornikiem początkowym wody czystej, które w razie wystąpienia sytuacji kryzysowej mogą stanowić źródło wody dla miasta.

Opracowana metodyka może wskazywać kierunek rozwoju dla przedsiębiorstw wodociągowych $\mathrm{w}$ zakresie rozbudowy systemu zabezpieczenia mieszkańców przed spożyciem skażonej wody.

\section{Literatura}

[1] Bajer J., Wieczysty A.: Analiza wpływu zbiorników wody surowej na podniesienie niezawodności układów zasilania w wodę, Monografie Komitetu Inżynierii Środowiska Polskiej Akademii Nauk, Vol. 2. Metody oceny i podnoszenia niezawodności działania komunalnych systemów zaopatrzenia w wodę, Wydawca: Komitet Inżynierii Środowiska PAN, Kraków 2001, 83-140.

[2] Croddy E., Perez-Armendariz C., Hart J.: Broń chemiczna i biologiczna. WNT, Warszawa 2003.

[3] Hamrol A., Mantura W.: Zarządzanie jakością - teoria i praktyka, Wydawnictwo Naukowe PWN, Warszawa - Poznań 1999.

[4] Mulik B., Parafińska K., Zimoch I., Marcinkowski J. T.: Zagrożenie zdrowotne związane $\mathrm{z}$ wodą przeznaczoną do spożycia w krajach o wysokim stopniu rozwoju. Technologia wody, 2/2015, 52 - 59.

[5] Oniszczuk A.: Prawo jednostki do wody jako konsekwencja prawa do życia. Możliwość realizacji prawa na przykładzie Bliskiego Wschodu. Wydawnictwo Beta-Druk; Wydział Prawa, Administracji i Ekonomii Uniwersytetu Wrocławskiego, Wrocław 2013, 7, $281-311$.

[6] Pillay A., Wang J.: Modified failure mode and effects analysis using approximate reasoning. Reliability Engineering and System Safety, 79/2003, $69-85$.

[7] Rak J.: Metoda szacowania ryzyka zagrożenia systemu zaopatrzenia w wodę, Ochrona Środowiska, 2/2003, $33-36$.

[8] Rak J. i inni: Metody oceny niezawodności i bezpieczeństwa dostawy wody do odbiorców, Oficyna wydawnicza Politechniki Rzeszowskiej, Rzeszów 2013.

[9] Rak J. i inni: Niezawodność i bezpieczeństwo systemów zbiorowego zaopatrzenia w wodę. Oficyna wydawnicza Politechniki Rzeszowskiej, Rzeszów 2012. 
Analysis and assessment of the security method against incidental contamination... Analiza i ocena zabezpieczenia systemów zbiorowego zaopatrzenia w wodę...

[10] Rak J., Szpak D.: Bezpieczeństwo sanitarno - higieniczne i działania osłonowe w sytuacjach kryzysowych związanych z zaopatrzeniem w wodę, Technologia wody, 6/2014, $10-14$.

[11] Rak J., Tchórzewska - Cieślak B.: The possible use of the FMEA method to ensure health safety of municipal water, Journal of KONBiN 2010, No. 2, 3 $(14,15), 143-154$.

[12] Rozporządzenie Ministra Środowiska z dnia 27 listopada 2002 r. w sprawie wymagań, jakim powinny odpowiadać wody powierzchniowe wykorzystywane do zaopatrzenia ludności w wodę przeznaczoną do spożycia (Dz.U. $2002 \mathrm{nr} 204$ poz. 1728).

[13] Rozporządzenie Ministra Zdrowia z dnia 29 marca 2007 roku w sprawie jakości wody przeznaczonej do spożycia przez ludzi (Dz.U. $2007 \mathrm{nr} 61$ poz. 417) wraz ze zmianami z 20 kwietnia 2010 roku (Dz.U. $2010 \mathrm{nr} 72$ poz. 466).

[14] Studziński A., Pietrucha - Urbanik K., Mędrala A.: Analiza strat wody oraz awaryjności $\mathrm{w}$ wybranych systemach zaopatrzenia $\mathrm{W}$ wodę. Czasopismo Inżynierii Lądowej, Srodowiska i Architektury. Oficyna Wydawnicza Politechniki Rzeszowskiej. t. XXXI, z. 61 (4/14), październik - grudzień 2014, $193-201$.

[15] Szpak D., Tchórzewska - Cieślak B.: Źródła zdarzeń incydentalnych w systemie zbiorowego zaopatrzenia w wodę. Mat. konf. XLIII Zimowa Szkoła Niezawodności „Niezawodność Systemów Technicznych”.

[16] Tchórzewska - Cieślak B.: Metody analizy i oceny ryzyka awarii podsystemu dystrybucji wody. Oficyna Wydawnicza Politechniki Rzeszowskiej, Rzeszów 2011.

[17] Tchórzewska- Cieślak B., Piegdoń I., Boryczko K.: Wykorzystanie nowoczesnych technik informatycznych oraz baz danych $w$ analizach ryzyka awarii podsystemu dystrybucji wody. Instal 6/2014, $76-79$.

[18] Tchórzewska - Cieślak B., Piegdoń I., Szpak D.: Water supply of urban agglomeration in crisis situation. Journal of Polish Safety and Reliability Association, Summer Safety and Reliability Seminars 2014, Vol. 5, No. 1, 143-154.

[19] Wang Y. M., Chin K. S., Poon G. K. K., \& Yang J. B.: Risk evaluation in failure mode and effects analysis using fuzzy weighted geometric mean. Expert Systems with Applications, 36/2009, 1195 - 1207.

[20] Wieczysty A., Rak J.: Niezawodność systemów zaopatrzenia w wodę w aspekcie wymagań jakościowych. Ochrona Środowiska, 1(56)/1995, 5 - 10.

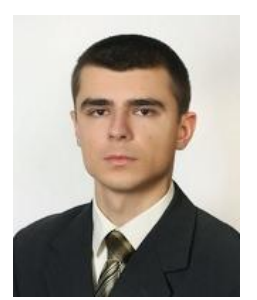

Mgr inż. Dawid Szpak w roku 2013 ukończyt studia na Wydziale Budownictwa i Inżynierii Srodowiska Politechniki Rzeszowskiej. Pracuje na stanowisku asystenta w Katedrze Zaopatrzenia w Wodę i Odprowadzania Ścieków Politechniki Rzeszowskiej. Zainteresowania naukowe: niezawodność $i$ bezpieczeństwo systemów zaopatrzenia $w$ wodę, zdarzenia incydentalne $w$ systemach zaopatrzenia $w$ wodę.

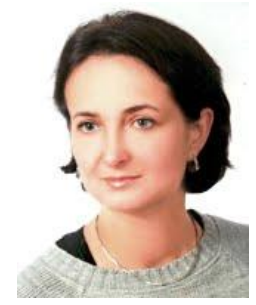

Dr hab. inż. Barbara Tchórzewska - Cieślak, prof. PRz pracuje na stanowisku profesora nadzwyczajnego $w$ Katedrze Zaopatrzenia $w$ Wodę i Odprowadzania Scieków Politechniki Rzeszowskiej. Zainteresowania naukowe: systemy zaopatrzenia $w$ wodę, niezawodność $i$ bezpieczeństwo systemów inżynierskich, niekonwencjonalne metody analizy i oceny ryzyka. 